OPEN ACCESS

Edited by: Grazia Terrone, University of Foggia, Italy

Reviewed by: Nicole Anderson, Brigham Young University,

United States

Robert Kelvin Perkins,

Norfolk State University, United States

${ }^{*}$ Correspondence:

Shervin Assar

assari@umich.edu

Specialty section:

This article was submitted to Gender, Sex and Sexuality Studies, a section of the journal

Frontiers in Psychology

Received: 19 January 2018

Accepted: 16 October 2018

Published: 16 November 2018

Citation:

Assari S, Mistry R, Caldwell CH and Zimmerman MA (2018) Marijuana

Use and Depressive Symptoms; Gender Differences in African

American Adolescents.

Front. Psychol. 9:2135.

doi: 10.3389/fpsyg.2018.02135

\section{Marijuana Use and Depressive Symptoms; Gender Differences in African American Adolescents}

\author{
Shervin Assari 1,2,3*, Ritesh Mistry ${ }^{3}$, Cleopatra Howard Caldwell ${ }^{2,3}$ and \\ Marc A. Zimmerman ${ }^{3}$ \\ ${ }^{1}$ Department of Psychiatry, School of Medicine, University of Michigan, Ann Arbor, MI, United States, ${ }^{2}$ Center for Research \\ on Ethnicity, Culture and Health, School of Public Health, University of Michigan, Ann Arbor, MI, United States, ${ }^{3}$ Department \\ of Health Behavior and Health Education, School of Public Health, University of Michigan, Ann Arbor, MI, United States
}

Introduction: This study aimed to examine gender differences in the bidirectional associations between marijuana use and depressive symptoms among African American adolescents. The study also tested gender differences in the effects of socioeconomic status, maternal support, and friends' drug use on adolescents' depressive symptoms and marijuana use.

Methods: This is a secondary analysis of the Flint Adolescent Study (FAS). Six hundred and eighty one African American adolescents (335 males and 346 females) were followed for 3 years, from 1995 (mean age 16) to 1997 (mean age 19). Depressive symptoms (Brief Symptom Inventory) and marijuana use were measured annually during the follow up. We used multi-group latent growth curve modeling to explore the reciprocal associations between depressive symptoms and marijuana use over time based on gender.

Results: Baseline marijuana use was predictive of an increase in depressive symptoms over time among male but not female African American adolescents. Baseline depressive symptoms were not predictive of an increase in marijuana use among male or female adolescents.

Conclusion: Study findings suggest that male African American adolescents who use marijuana are at an increased risk of subsequent depressive symptoms. Interventions that combine screening and treatment for marijuana use and depression may be indicated for African American male adolescents.

Keywords: marijuana use, depression, African American, gender, adolescents

\section{INTRODUCTION}

Overall, African American individuals have lower rates of major depressive disorder (MDD) (Blazer et al., 1994; Kessler et al., 1994; Williams et al., 2007) but higher levels of depressive symptoms (Blazer et al., 1998) relative to White Americans. Possibly due to a lower access to the health care system and a higher stigma associated with mental health problems (Menke and Flynn, 2009), depression tends to be more chronic, severe, and disabling for African American individuals compared to White Americans (Jones-Webb and Snowden, 1993; Williams et al., 2007). 
Marijuana is one of the most frequently used drugs by African American adolescents (CDC, 1998; Miech et al., 2017). While African American adolescents are less likely to use marijuana compared to their White counterparts, the consequences of drug use may be more devastating for them (Wallace and Bachman, 1993). Given their lower access and adherence to treatment (Cook and Alegría, 2011; Mericle et al., 2012; Schildhaus and Dugoni, 2012; Simoni et al., 2012; Acevedo et al., 2015; Hamilton et al., 2015; Mennis and Stahler, 2016), marijuana use is known to be associated with worse health outcomes among African American compared to White Americans (Watts and Wright, 1990; Pacek et al., 2012; Peters et al., 2014).

Marijuana use and depression tend to be comorbid among adolescents (Medina et al., 2007; Repetto et al., 2008; Crane et al., 2015). Individuals who use marijuana (Brown et al., 1996; Degenhardt et al., 2003; Volkow, 2004; Libby et al., 2005) and other substances such as tobacco (Boden et al., 2010; Weinstein and Mermelstein, 2013) report higher levels of depressive symptoms than non-users. Although some research has shown that marijuana use and depressive symptoms may have reciprocal effects on each other (Degenhardt et al., 2003; Patton et al., 2005), most of the existing knowledge is from studies with predominantly White samples (Degenhardt et al., 2003; Patton et al., 2005; Crane et al., 2015). Therefore, there is a need to study these associations specifically among African American adolescents (Kandel et al., 1997; Repetto et al., 2008; Caldwell et al., 2016).

Although recent evidence has suggested that the link between depressive symptoms and marijuana use may differ based on gender (Crane et al., 2015), less is known about such gender differences among African American adolescents (Kandel et al., 1997; Wallace et al., 1999; Repetto et al., 2008). Knowledge about between- and within-group differences is essential for finding racial/ethnic specific and culturally relevant solutions for prevention and control of common mental and behavioral comorbidities associated with marijuana use among male and female African American adolescents (Repetto et al., 2008).

The link between marijuana use and depression can be explained by both psychosocial as well as biological mechanisms. Among various psychosocial theories that explain the link between substance use and depression, Negative Effects Model suggests that depression is a consequence for marijuana use. In this view, behavioral maladjustment (e.g., marijuana use) precedes affective problems (Costello et al., 1999; Armstrong and Costello, 2002). Baseline substance use in this perspective is associated with negative social interactions that increase subsequent risk of depression (Aseltine and Gore, 1998). In a study, Repetto et al. (2008) found that depressive symptoms precede marijuana use among male African American adolescents.

There are also biological explanations for this link. The endogenous cannabinoid system (ECS) is distributed throughout several brain regions including prefrontal cortex, hippocampal regions, as well as white matter (Romero et al., 1997, 2002; Iversen, 2003). Animal studies have documented cellular effects of marijuana use in hippocampal regions (Stiglick and Kalant, 1985; Childers and Breivogel, 1998; Pistis et al., 2004). Human studies have also documented structural brain changes associated with marijuana use (Verdejo-García et al., 2004). Damage to the cannabinoid system may result in depressive-like symptoms (Martin et al., 1996). Some Aasly et al. (1993) and Matochik et al. (2005) but not all Block et al. (2000) and Wilson et al. (2000) human studies have found gray and white matter abnormalities among marijuana users. In a study, marijuana use interacted with white matter volume in predicting depressive symptoms. In marijuana users, but not in controls, white matter volume was inversely associated with depressive symptoms (Medina et al., 2007). In another study, marijuana use interacted with gender on brain measures on the size of prefrontal cortex, with male marijuana users showing a smaller prefrontal cortex volume compared to other groups (Medina et al., 2009).

There is some evidence suggesting that gender may moderate these links. Most research on gender differences in the link between depressive symptoms and marijuana use, however, has been conducted in predominately White populations. African American males and females differ in using behavioral coping to environmental stress (Jackson et al., 2010). While African American males may turn to substance use (Assari et al., in press) and depression (Assari et al., 2017), African American females may have a higher tendency for over eating and obesity (Assari, 2018). As a result, we expect a stronger association between depression and substance use for males than females. In addition, some research has suggested that family support and family SES may have different implications for the health of male and female African American adolescents (Assari et al., 2018). For instance, in one study, maternal support predicted depressive symptoms and obesity for male and female African American adolescents, respectively (Assari et al., 2015).

Building on previous studies on the same topic (Repetto et al., 2008; Crane et al., 2015), the goal of the current study was to explore gender differences in the bidirectional relationships between marijuana use and depression symptoms among African American adolescents. Structural equation modeling (SEM) allows us to test reciprocal associations between marijuana use and depressive symptoms over time. We hypothesized that baseline marijuana use would be related to an increase in symptoms of depression, especially for males (Hypothesis 1). We also hypothesized that symptoms of depression at baseline will predict more marijuana use among males (Hypothesis 2).

\section{MATERIALS AND METHODS}

\section{Study Design and Setting}

Using a longitudinal design, this is a secondary data analysis of the first four waves of a parent study, the Flint Adolescent Study (FAS). The FAS is a 12-wave longitudinal study (over a period of 18 years) of adolescents from adolescence through their transition to early adulthood.

\section{Sampling}

All participants were enrolled from Flint, MI, an economically challenged city in the Midwest of the United States. The original FAS enrolled 850 9th graders, in collaboration with the Flint 
Community Schools. Participants were sampled from four local public high schools. As the primary goal of the study was school dropout, students with a grade point average (GPA) of 3.0 and below were selected. All participants were 9th graders at the start of the study. Having a defined diagnosis of developmental or emotional disability/impairment were exclusion criteria. The study followed the adolescents during their high school years. The study had a $90 \%$ response rate from Waves 1 to 4 . Mean age of the participants at baseline was 15 years. The FAS sample had an almost equal number of males and females, and was reflective of the overall student body in the Flint High Schools in the Fall in the year 1994 (Aiyer et al., 2014; Assari et al., 2014). Six hundred eighty-one (681) African American adolescents (335 males and 346 females) were included in the current study. Non-African American individuals were excluded from the analytic sample. Age, gender, and socioeconomic status were measured at baseline (9th grade), maternal support and friends' drug use was collected at Wave 2, and marijuana use and depressive symptoms were measured at Wave 2 (10th grade), Wave 3 (11th grade), and Wave 4 (1 year after high school).

\section{Ethics}

Written informed consent was obtained from parents of participating adolescents. All participants provided written consent or assent before each interview, depending the age of the participant at the time of the interview. The study protocol was approved by the University of Michigan (UM) Institutional Review Board.

\section{Procedures}

Face-to-face interviews were used in the data collection. The interviews were conducted either at school or at an alternative community location such as church. Interviews lasted about $1 \mathrm{~h}$ on average. Data collection continued regardless of the school dropout status of the participants.

\section{Measures Covariates}

Age (continuous measure), gender (female vs. male, with male as the reference category), and family socioeconomic status were measured at baseline. Family socioeconomic status was defined as parental employment status and family structure. SES (parental employment) was self-reported. SES was operationalized as a dichotomous variable (both parents employed vs. less than two parents were employed). Family structure was also conceptualized as a dichotomous variable (both biological parents available vs. any other conditions) (Appendix Table A1).

\section{Maternal Support}

In this study we only used maternal, not paternal, support because a large proportion of adolescents did not report information about their biological fathers due to adolescents not knowing them, not having any real relationship with them, or because they were either in prison or deceased. This is partially due to the fact that only $25 \%$ of the participants were living in an intact family at baseline. The maternal support measure in the current study was the modified measure for parental support developed by Procidano and Heller (1983). This measure had five items that assessed closeness of the parent-adolescents relationship as well as the amount that parent provided emotional and instrumental support for the adolescents. Items were on a five-point Likert scale, ranging from 1 (not true) to 5 (very true). A total score was created by calculating an average of all five items (Brenner et al., 2011). (Cronbach's alpha $=0.879$ ).

\section{Friends' Drug Use}

Friends drug use was measured by asking 10 questions. Sample items included "how many of your friends (1) smoke marijuana at least once a month? (2) have used cocaine? and (3) have used heroin or morphine?" Item response included a five category response, including none (1), some (2), many (3), most (4), and all (5). Total score was the average of all items, with higher score indicating more drug use among friends. This measure has been previously used (Elkington et al., 2011) (Cronbach's alpha $=0.869$ ).

\section{Depressive Symptoms}

Depressive symptoms were measured using the six items of the Brief Symptom Inventory (BSI; Derogatis and Spencer, 1982, 1993; Derogatis, 1977a). These items assess symptoms of depression such as feeling hopeless about the future and having no interest in things during the past week. Items used a five point Likert scale ranging from 1 (not at all uncomfortable) to 5 (extremely uncomfortable). We calculated a total score which was an averaged of all items. BSI has high reliability and validity in adolescents and adults (Derogatis, 1977b; Derogatis and Spencer, 1982, 1993) Cronbach's alpha was 0.8249 in our sample at Wave 1.

\section{Marijuana Use}

Borrowing from the Monitoring the Future Study (Bachman et al., 1997; Repetto et al., 2008), marijuana use was measured using three items that assess the number of times that the participant had used marijuana (grass, weed, pot, hashish) in his or her lifetime, last year, and the last 30 days. Response categories included: 0 times; $1-2$ times; $3-5$ times; 6-9 times; $10-19$ times; 20-39 times; and 40 or more times. Total score was the mean of the three items, ranging from 1 to 7 , with higher score indicating more use (Repetto et al., 2008). Cronbach's alpha was 0.897 at Wave 1 .

\section{Attrition Analysis}

Attrition analysis revealed that drop out was not at random. Loss to follow up (drop out) was associated with higher age, male gender, not living in an intact family, and having used more marijuana at baseline. Attrition was not associated with parental employment, maternal support, friends' drug use, and depressive symptoms.

\section{Data Analysis}

Univariate and bivariate analyses were conducted in SPSS 20.0 (IBM Corporation, Armonk, NY, United States). For bivariate analysis, Pearson's correlation test and also paired samples t-test were used. We used Analysis of Moment Structure (AMOS 18.0) for multivariable analysis (Allison, 2002; Arbuckle, 2009). 
For multivariable data analysis, we used multi-group latent growth curve modeling (LGCM). LGCM is a subtype of structural equation modeling (SEM) (Kline, 2011). We used LGCM rather than traditional SEM because we wanted to model trajectories rather than change (difference between two observations).

In the first step for LGCM, we fitted unconditional models of depressive symptoms and marijuana use. In the next step, we ran a parallel process model with two growth models for depressive symptoms and marijuana use. Then, we added all covariates. In all multi-group models, the group was defined based on gender. We did not constrain the paths across the groups in unconditional or conditional models with or without covariates (Kock, 2014). Fit statistics included were Chi square, $p$-value, the comparative fit index (CFI) [>0.90], the Chi square to degrees of freedom ratio, and Root Mean Squared Error of Approximation (RMSEA) [<0.06] (Tabachnick and Fidell, 1996; Hu and Bentler, 1999; Lei and Lomax, 2005). Standardized path coefficients were reported. AMOS applies the Full Information Maximum Likelihood (FIML) to handle the missing data. $P<0.05$ was considered as significant.

\section{RESULTS}

Table 1 summarizes descriptive statistics for demographic data, socioeconomic factors, maternal support, friends' drug use, marijuana use, and depressive symptoms. Paired samples $t$-test showed that marijuana use increased among males and females over time. Paired samples $t$-test did not show, however, any significant change in depressive symptoms in the pooled sample.

\section{Bivariate Analysis}

As Table 2 indicates, in the pooled sample, females were younger, were less likely to live in an intact family, reported lower maternal support, and higher depressive symptoms at baseline than males. Gender was not correlated with marijuana use at baseline. In the pooled sample, age showed a weak positive correlation and living in an intact family showed a weak negative correlation with frequency of marijuana use at baseline. Friends' drug use showed a strong positive correlation with marijuana use at baseline. Maternal support showed a weak negative correlation with frequency of marijuana use at baseline.

As shown in Table 3, age was positively correlated with baseline marijuana use for males, but not for females. Living in an intact family has a weak negative correlation with baseline marijuana use among both male and female adolescents. For both genders, friends' drug use showed moderate to strong correlation with baseline marijuana use. Among males, maternal support showed a weak positive correlation with marijuana use at baseline. Among females, maternal support was not correlated with baseline marijuana use.

\section{Multivariable Model}

The fit of the final multi-group path model was good $\left(\chi^{2}=138.037, d f=40, p<0.001, \chi^{2} / d f=3.451, \mathrm{RMSEA}=0.060\right.$; Figures 1, 2).

As depicted in Table 4 and Figure 1, among males, there was a significant and positive path from baseline marijuana use to change in depressive symptoms over time. Among males, age was negatively associated with baseline depressive symptoms; having an intact family was associated with lower baseline marijuana use and an increased change in marijuana use over time among

TABLE 1 | Descriptive statistics overall and by gender.

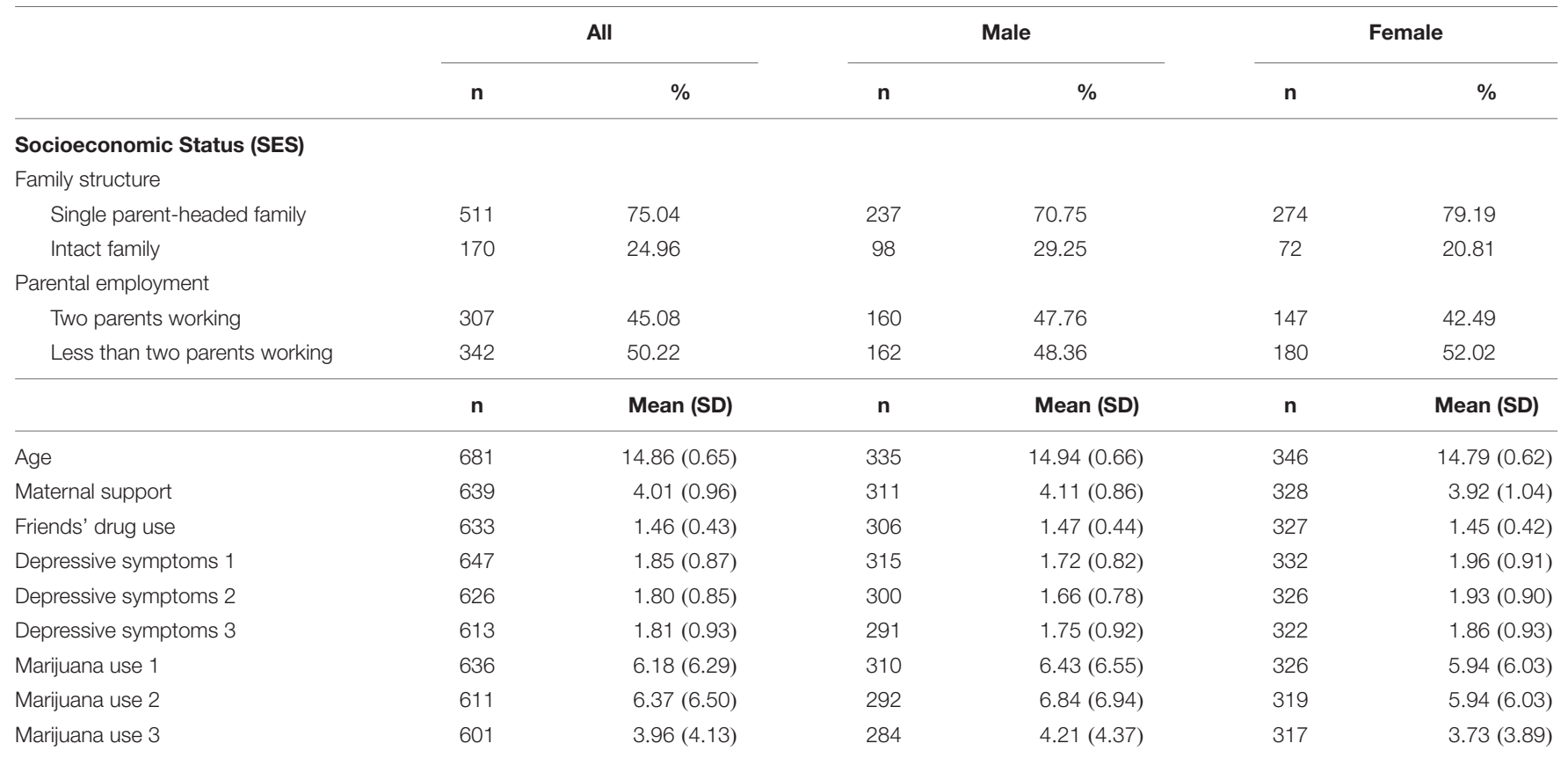


TABLE 2 | Correlation matrix among African American adolescents.

\begin{tabular}{|c|c|c|c|c|c|c|c|c|c|c|c|c|}
\hline & 1 & 2 & 3 & 4 & 5 & 6 & 7 & 8 & 9 & 10 & 11 & 12 \\
\hline 1 Gender (Female) & 1 & $-0.12^{* *}$ & $-0.10^{*}$ & -0.05 & $-0.10^{*}$ & -0.02 & $0.14^{* *}$ & $0.16^{* *}$ & 0.06 & -0.04 & -0.07 & -0.06 \\
\hline 2 Age & & 1 & $-0.10^{*}$ & $-0.09 *$ & -0.01 & $0.11^{* *}$ & -0.05 & -0.06 & -0.03 & $0.12^{* *}$ & 0.06 & -0.02 \\
\hline 3 Intact family & & & 1 & $0.14^{* *}$ & $0.10^{*}$ & -0.04 & $-0.09 *$ & 0.01 & -0.06 & $-0.15^{* *}$ & $-0.15^{* *}$ & -0.06 \\
\hline 4 Two parents working & & & & 1 & 0.05 & -0.07 & -0.05 & -0.01 & 0.01 & -0.04 & -0.02 & -0.03 \\
\hline 5 Maternal support & & & & & 1 & $-0.20^{* *}$ & $-0.18^{* *}$ & $-0.14^{* *}$ & $-0.13^{* *}$ & $-0.12^{* *}$ & $-0.16^{* *}$ & $-0.13^{* *}$ \\
\hline 6 Friends' drug use & & & & & & 1 & $0.13^{* *}$ & 0.04 & $0.08^{*}$ & $0.51^{* *}$ & $0.39^{* *}$ & $0.37^{* *}$ \\
\hline 7 Depressive symptoms 1 & & & & & & & 1 & $0.34^{* *}$ & $0.23^{* *}$ & 0.07 & 0.06 & 0.07 \\
\hline 8 Depressive symptoms 2 & & & & & & & & 1 & $0.36^{* *}$ & $0.12^{* *}$ & $0.12^{* *}$ & $0.13^{* *}$ \\
\hline 9 Depressive symptoms 3 & & & & & & & & & 1 & $0.11^{* *}$ & $0.09 *$ & $0.13^{* *}$ \\
\hline 10 Marijuana use 1 & & & & & & & & & & 1 & $0.69 * *$ & $0.60 * *$ \\
\hline 11 Marijuana use 2 & & & & & & & & & & & 1 & $0.72^{* *}$ \\
\hline 12 Marijuana use 3 & & & & & & & & & & & & 1 \\
\hline
\end{tabular}

${ }^{*} p<0.05 ; * * p<0.01$.

TABLE 3 | Correlation matrix among male and female African American adolescents.

\begin{tabular}{|c|c|c|c|c|c|c|c|c|c|c|c|}
\hline & 1 & 2 & 3 & 4 & 5 & 6 & 7 & 8 & 9 & 10 & 11 \\
\hline 1 Age & 1 & -0.10 & -0.10 & -0.05 & 0.11 & $-0.13^{*}$ & -0.10 & -0.07 & $0.13^{*}$ & 0.05 & -0.05 \\
\hline 2 Intact family & $-0.12^{*}$ & 1 & $0.15^{*}$ & $0.12^{*}$ & -0.06 & -0.07 & 0.04 & -0.07 & $-0.18^{* *}$ & $-0.19^{* *}$ & -0.07 \\
\hline 3 Two parents working & -0.10 & $0.13^{*}$ & 1 & $0.13^{*}$ & $-0.12^{*}$ & -0.11 & 0.05 & 0.02 & -0.09 & -0.04 & -0.06 \\
\hline 4 Maternal support & -0.01 & 0.06 & -0.02 & 1 & $-0.25^{* *}$ & $-0.15^{* *}$ & -0.09 & -0.01 & $-0.16^{* *}$ & $-0.19 * *$ & $-0.12^{*}$ \\
\hline 5 Friends' drug use & $0.12^{*}$ & -0.02 & 0.02 & $-0.16^{* *}$ & 1 & 0.11 & 0.08 & 0.03 & $0.46^{* *}$ & $0.40^{* *}$ & $0.32^{* *}$ \\
\hline 6 Depressive symptoms 1 & 0.03 & -0.08 & 0.01 & $-0.18^{* *}$ & $0.16^{* *}$ & 1 & $0.27^{* *}$ & $0.19^{* *}$ & 0.07 & $0.12^{*}$ & 0.06 \\
\hline 7 Depressive symptoms 2 & 0.01 & 0.01 & -0.03 & $-0.16^{* *}$ & 0.01 & $0.37^{* *}$ & 1 & $0.33^{* *}$ & $0.15^{*}$ & $0.19^{* *}$ & $0.18^{* *}$ \\
\hline 8 Depressive symptoms 3 & 0.02 & -0.05 & 0.02 & $-0.21^{* *}$ & $0.13^{*}$ & $0.26^{* *}$ & $0.39^{* *}$ & 1 & $0.12^{*}$ & 0.11 & $0.17^{* *}$ \\
\hline 9 Marijuana use 1 & 0.10 & $-0.12^{*}$ & 0.01 & -0.11 & $0.56^{* *}$ & 0.08 & $0.11^{*}$ & 0.11 & 1 & $0.68^{* *}$ & $0.55^{* *}$ \\
\hline 10 Marijuana use 2 & 0.06 & $-0.12^{*}$ & -0.02 & $-0.15^{*}$ & $0.38^{* *}$ & 0.03 & 0.09 & 0.09 & $0.71^{* *}$ & 1 & $0.74^{* *}$ \\
\hline 11 Marijuana use 3 & 0.01 & -0.06 & -0.01 & $-0.15^{*}$ & $0.42^{* *}$ & 0.09 & 0.10 & 0.10 & $0.65^{* *}$ & $0.70^{* *}$ & 1 \\
\hline
\end{tabular}

Males upper diagonal (in bold), females lower diagonal. * $p<0.05$; ** $p<0.01$.

male adolescents. Friends' drug use was positively associated with baseline marijuana use. Maternal support was not associated with baseline or change in marijuana use over time among males.

As shown in Table 4 and Figure 2, among females, there were no significant paths from baseline depressive symptoms or marijuana use to change in depressive symptoms or marijuana use over time. Age and parent employment were not associated with baseline or change of depressive symptoms or marijuana use. Higher maternal support was associated with lower depressive symptoms at baseline.

\section{DISCUSSION}

Our study had at least three main findings. First, there was a gender difference in the association between marijuana use and depressive symptoms with the association being present only for male, but not female, African American adolescents. Second, baseline marijuana use predicted the trajectory of depressive symptoms over time for males. Third, baseline depressive symptoms were not predictive of change in marijuana use over time for either gender.
Our findings extend the existing literature which is mostly limited to White participants (Rohde et al., 1991; Kandel et al., 1997; Rao et al., 2000; Swendsen and Merinkangas, 2000). Our first result on gender difference in the association between marijuana use and depressive symptoms among adolescents was in line with the results reported by Schuster et al. (2013); Repetto et al. (2008), and Crane et al. (2015) who all documented gender as a moderator for the same association. Our second finding documented paths from baseline marijuana use to subsequent depressive symptoms is in line with the some (Green and Ritter, 2000; Bovasso, 2001; Arseneault et al., 2002; Brook et al., 2002; Fergusson et al., 2002; Patton et al., 2002) but not all (Repetto et al., 2008).

Males and females differ in how they develop comorbid depression and marijuana use (Kandel, 1984; Fergusson and Horwood, 1997; Scaramella et al., 1999; Griffin et al., 2000; Assari et al., 2015; Crane et al., 2015) and African American adolescents are not exception to this rule. In a majority White sample, Crane et al. (2015) found a link between symptoms of depression and marijuana use among 15-16 years old boys, but not girls. In another study by Repetto et al. (2008) of 622 African American adolescents transitioning into young adulthood, baseline depressive symptoms predicted subsequent 


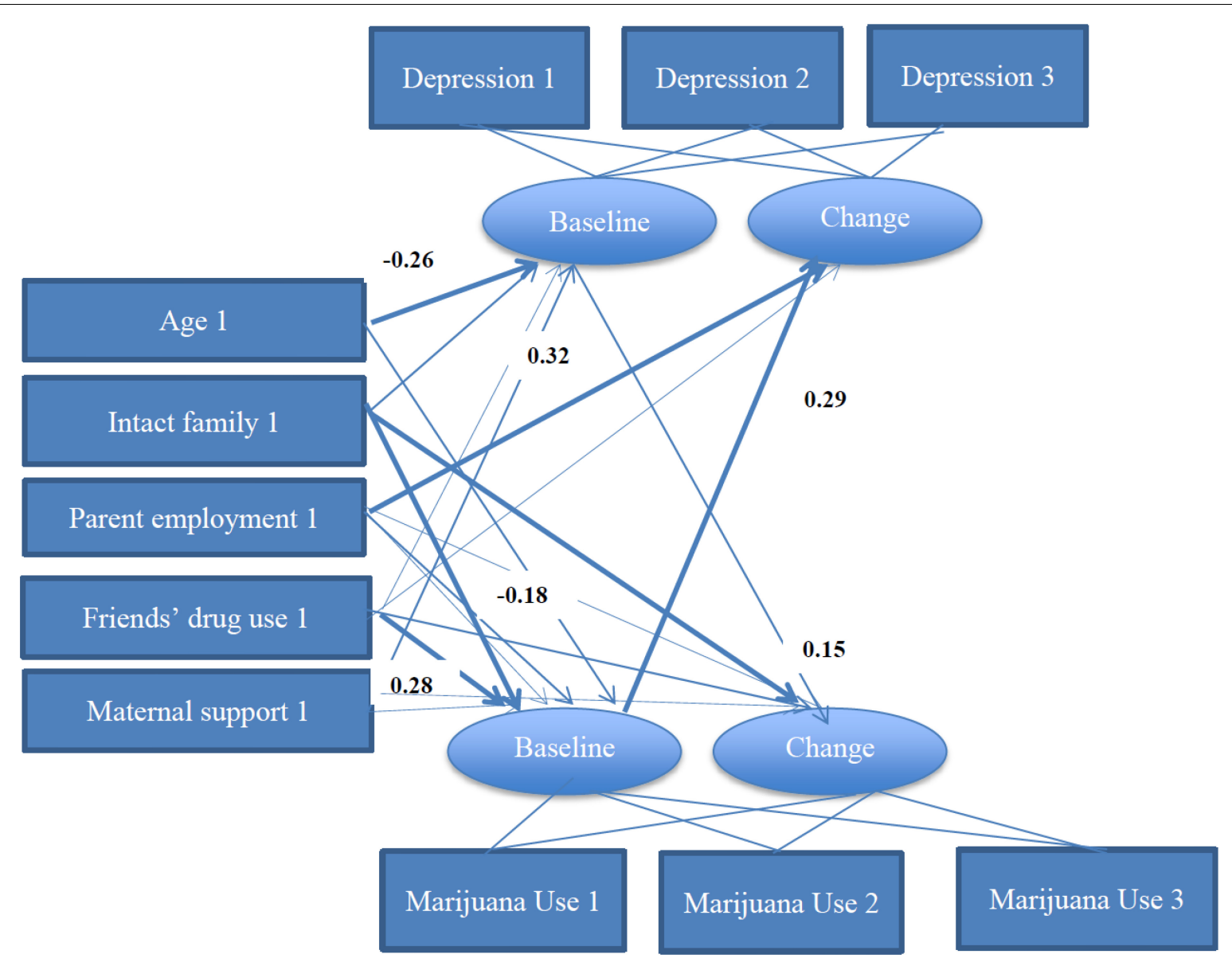

FIGURE 1 | Summary of path coefficients among male African American adolescents [ $\chi^{2}=138.037, p<0.001, d f=40, \chi^{2} / d f=3.451$, Root Mean Squared Error of Approximation $(\mathrm{RMSEA})=0.060$ ]. Numbers reflect standardized regression coefficients that are adjusted for other variables. Bold paths reflect significant effects.

marijuana in males, while baseline marijuana use did not correlate with future increase in depressive symptoms for females or males.

Our findings suggest that marijuana use has a stronger negative effect on psychological wellbeing of male African American adolescents, compared to their female counterparts. Literature has mentioned that marijuana use may be a coping mechanism for African American males who deal with psychological distress (Schuster et al., 2013) and discrimination (Gerrard et al., 2012). Males are more likely to use external avoidance-based coping strategies, such as substances, to cope with negative affect (Hankin et al., 2007), while females may have a higher tendency to use internalizing coping strategies, such as rumination and isolation (Copeland and Hess, 1995; Hankin et al., 2007). Gender differences in social and environmental influences on marijuana use are also reported (Caggiula et al., 2002; Shrier et al., 2012; Crane et al., 2013). These may be also related to sex differences in brain connectivity (Lei et al., 2016; Conrin et al., 2018).

With some gender differences, parental support was found to protect adolescents against depression and substance use, which is in line with previous research (Wills and Vaughan, 1989;
Wills et al., 1996, 2000; Assari et al., 2015). Friends' drug use also differently influences drug use among boys and girls (Schulte et al., 2009). While conflict with a parent is a risk factor for substance use (Farrell and White, 1998), positive family relations that manifest in different forms such as affection, praise, and encouragement, may lower adolescents' drug use (Barber, 1992; Knight et al., 1998). The protective effect of parental support against adolescent substance use is shown to be above and beyond peers' influence (Bahr et al., 1995; Branstetter et al., 2011). Parental support reduces substance use through enhancing self-control and behavioral coping and reducing overall risk-taking tendency and tolerance for deviance (Wills et al., 1996, 2004). The effect of parental support on depression is also mediated by self-evaluation (Valiente et al., 2014).

Although adolescents are trying to individuate themselves from parents during this developmental period, they still need parental support (Settersten and Ray, 2010). The protective effects of parental support on depressive symptoms (Gore and Aseltine, 2003; Miller and Taylor, 2012) and substance use (Ralston et al., 2012) remain during the transition to adulthood. Yet, the links between family resources, depression, and substance use may depend on gender, race, and socioeconomic 


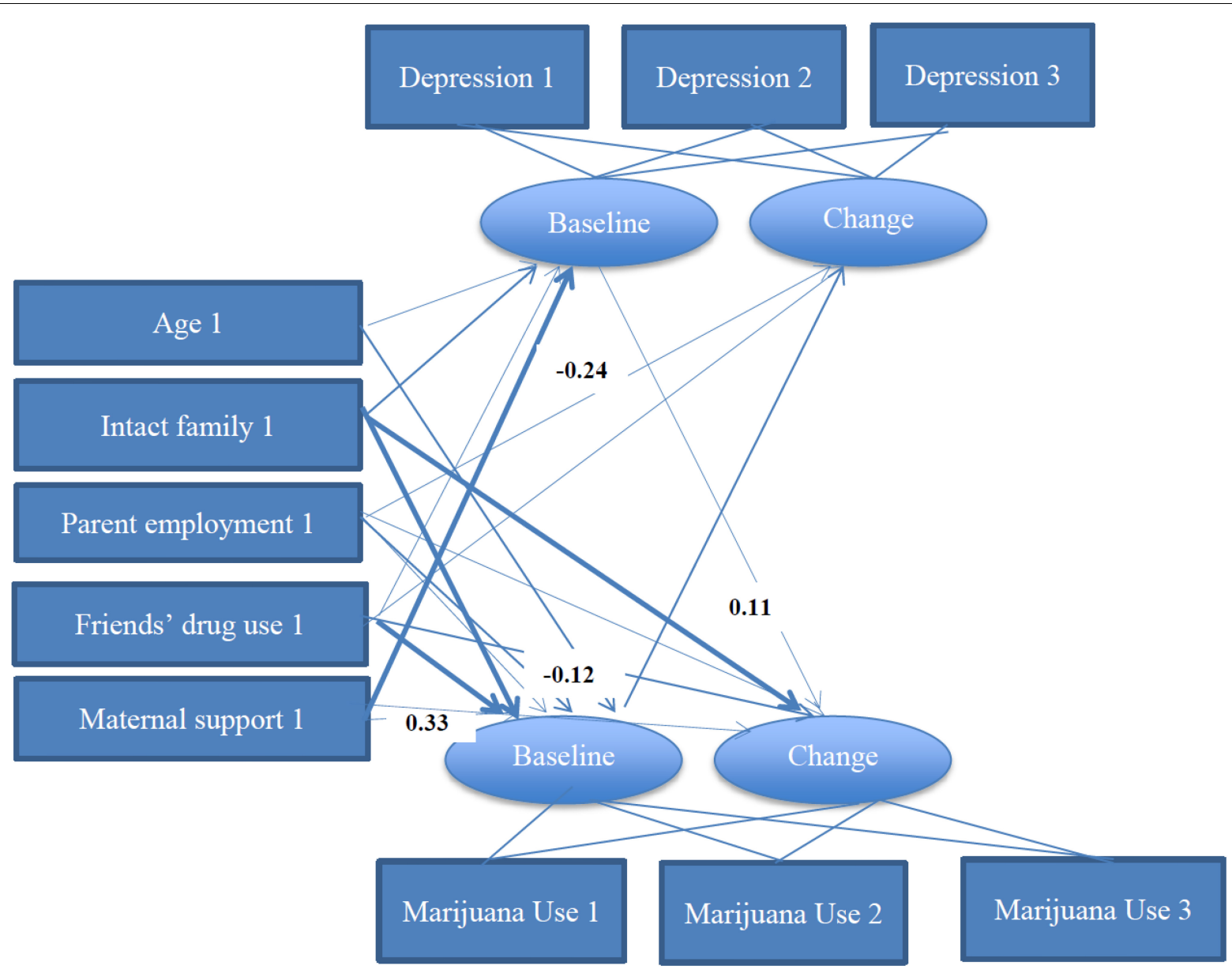

FIGURE 2 | Summary of path coefficients among female African American adolescents $\left[x^{2}=138.037, p<0.001, d f=40, \chi^{2} / d f=3.451\right.$. Root Mean Squared Error of Approximation $(\mathrm{RMSEA})=0.060$ ]. Numbers reflect standardized regression coefficients that are adjusted for other variables. Bold paths reflect significant effects.

TABLE 4 | Summary of path coefficients among male and female African American adolescents.

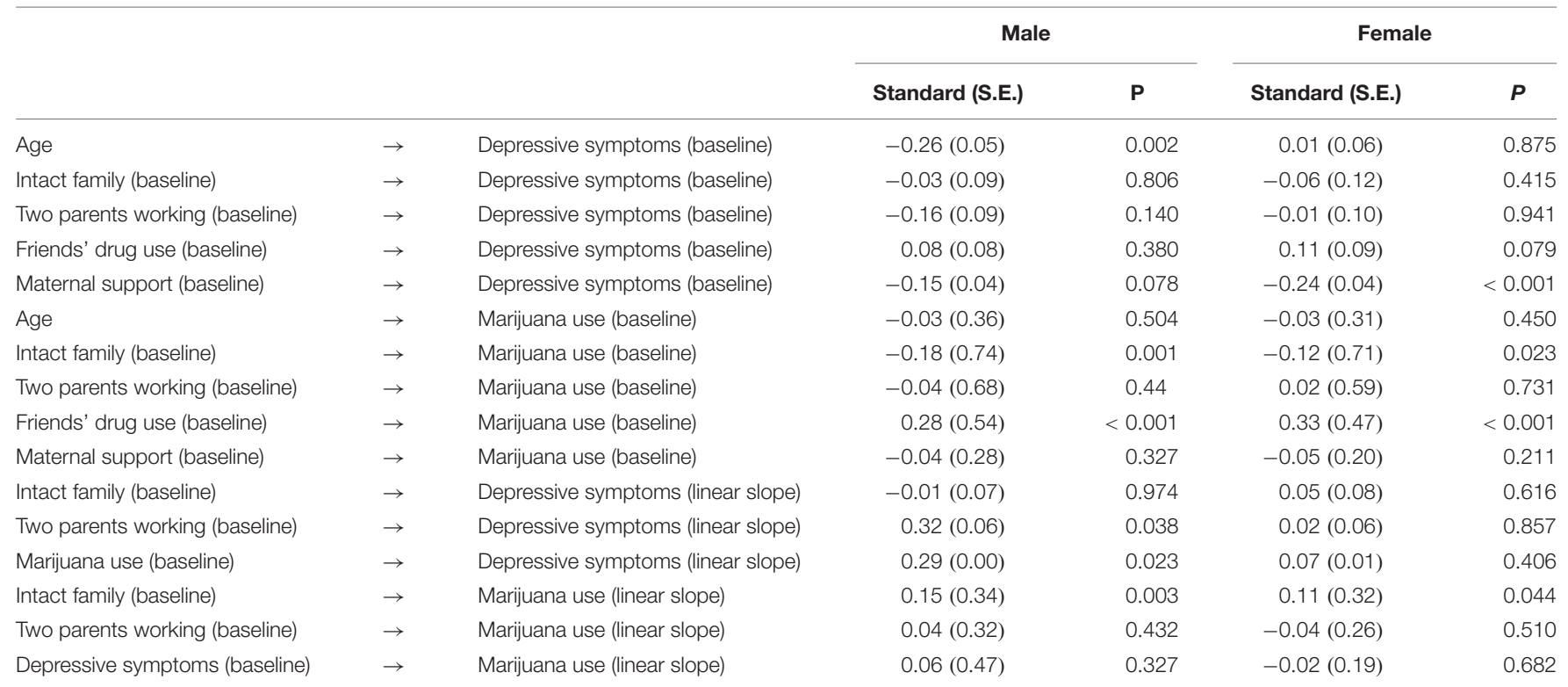


status (Miller and Taylor, 2012). This study demonstrated the unique role of gender in shaping the effect of parenting on changes in depression and substance use of African American adolescents.

Marijuana use is associated with depression (Degenhardt et al., 2003; Klungsoyr et al., 2006; Mathers et al., 2006; Cuijpers et al., 2007; Hayatbakhsh et al., 2007; van Laar et al., 2007; Pedersen and von Soest, 2009; Brook et al., 2012; CDC, 2012, 2013), particularly in those with early initiation (Silins et al., 2014), however, these links are not constant across genders. Gender influences the prevalence and pattern of marijuana use (SAMSHA, 2013; Johnston et al., 2014) and depression (Hankin and Abramson, 1999; Piccinelli and Wilkinson, 2000; Kuehner, 2003). Understanding how gender moderates the link between symptoms of depression and marijuana use may inform design and evaluation of prevention and treatment programs for African American adolescents.

According to the literature, comorbid depression is associated with earlier onset of drug use (Rohde et al., 1996; Rao et al., 1999), as well as worse drug use outcomes (Rohde et al., 1996; Whitmore et al., 1997) such as delayed recovery (Mallin et al., 2002). Among those who are depressed, comorbid substance use is a predictor of longer depressive episodes (Riggs et al., 1995; King et al., 1996) and higher suicide risk (Bukstein et al., 1993). Extending the literature on how gender alters risk of comorbidity between depression and marijuana use may inform the policies and programs that can be used for prevention and treatment of adolescents that present with comorbid depression and marijuana use.

Our findings are particularly important because marijuana is the most commonly used drug in adolescence (CDC, 2000; Miech et al., 2017) and transition to adulthood (Bachman et al., 1997; Schulenberg et al., 2017) in the United States. These transition periods are the stages of identity development, and are characterized by change and exploration (Arnett, 2002). In these periods, individuals begin managing new roles and responsibilities (Arnett, 2002).

These findings have important implications particularly because of the possibility of an increase in availability of marijuana due to legalization of medical marijuana in the United States (McKenna, 2014; Onders et al., 2015). Marijuana is the most commonly used substance by African American adolescents (CDC, 1998; Miech et al., 2017) and consequences associated with substance use are higher and more devastating for African American adolescents (Wallace and Bachman, 1993). Adolescents may self-medicate using marijuana to cope with the changes and new responsibilities that are a part of their transition into and from adolescence (Chen and Kandel, 1998). Adolescents may also use marijuana under influence of their peers (Dishion and Loeber, 1985; Chabrol et al., 2008). Our findings suggest that African American male adolescents who use marijuana should be screened for depression.

Evidence-based interventions and programs that can prevent substance use in adolescents exist (Griffin and Botvin, 2010). Programs should promote parental support that African American adolescents receive (Caldwell et al., 2004). As substance use in social networks is a main determinant of adolescents' substance use (Tucker et al., 2015), programs may promote greater involvement of at risk adolescents in non-drug using social networks. Evidence-based interventions should be widely implemented in the communities where most at risk adolescents live (Hawkins et al., 2002).

The current study has a few limitations. First and foremost, this study did not enroll a random sample of adolescents. The study did not use a probability sampling framework and the sample was drawn from a single city in Midwest. As a result, our findings are not generalizable to all African American adolescents in the United States. Yet, so few studies have focused on the research questions addressed in the current study. The findings are a useful early step and suggest that more representative sample studies would be a useful next step. Second, the data were old and much has changed regarding psychological impact of marijuana use in adolescents. Legalization of medical marijuana in some US states may have reduced stigma associated with its use. There is a need to replicate these findings in newer data sets. Third, all variables in this study were conceptualized and measured at the individual level, and higher-level ecological factors (availability and acceptability of marijuana, area level socioeconomic status, and racial composition of the neighborhood) were not included. This may be especially important for studies on non-majority adolescents, as experiences of discrimination may weigh on them and influence both their depression and substance use. Nevertheless, our study suggests that individual level factors matter and that examining larger structural factors associated with them may be a vital next step for understanding the process by which individual behaviors manifest themselves. Fourth, our parental support measure was limited to maternal support, as a considerable proportion of our adolescents were not in relation with their fathers. We do know that fathers play a vital role in adolescent development (Salem et al., 1998; Ozer et al., 2013; Caldwell et al., 2014) as well, so future research that specifically includes them would be worthwhile. Yet, the study of mother support adds to our vast knowledge about her vital role in adolescent development. Fifth, attrition was not at random, and individuals who stayed in the study had lower age, were more often females, more frequently lived in an intact family, and used less marijuana at baseline. Despite these limitations, the current study makes a significant contribution to the literature.

\section{CONCLUSION}

To conclude, the findings presented here revealed that male and female African American adolescents differ in the reciprocal associations between marijuana use and depressive symptoms. Male African American adolescents who use marijuana may be at higher risk of elevated depressive symptoms over time. As a result, male African American adolescents who use marijuana may benefit from combined programs that simultaneously treat depression. Necessity for such combined programs is less evident for female African American adolescents, whose 
marijuana use and depressive symptoms seem to be unrelated. Maternal support was also differently linked to marijuana use and depressive symptoms among male and female African American adolescents. As a result, male and female African American adolescents may differently benefit from programs that enhance maternal social support.

\section{AUTHOR CONTRIBUTIONS}

The original idea of this analysis was developed by SA. SA also analyzed the data and drafted the manuscript. MZ designed the main cohort study, acquired the data, and RM, CC, and MZ contributed to all drafts of this manuscript. All authors confirmed the final version of the manuscript.

\section{REFERENCES}

Aasly, J., Storsaeter, O., Nilsen, G., Smevik, O., and Rinck, P. (1993). Minor structural brain changes in young drug abusers. Acta Neurol. Scand. 87, 210-214. doi: 10.1111/j.1600-0404.1993.tb04103.x

Acevedo, A., Garnick, D., Ritter, G., Horgan, C., and Lundgren, L. (2015). Race/ethnicity and quality indicators for outpatient treatment for substance use disorders. Am. J. Addict. 24, 523-531. doi: 10.1111/ajad. 12256

Aiyer, S. M., Heinze, J. E., Miller, A. L., Stoddard, S. A., and Zimmerman, M. A. (2014). Exposure to violence predicting cortisol response during adolescence and early adulthood: Understanding moderating factors. J. Youth Adolesc. 43, 1066-1079. doi: 10.1007/s10964-014-0097-8

Allison, P. D. S. (2002). E.M.W.A.B.C., Applications, and Programming, 2nd Edn. New York, NY: Taylor and Francis Group.

Arbuckle, J. L. (2009). Amos Development Corporation. Available at: http:// amosdevelopment.com/

Armstrong, T. D., and Costello, E. J. (2002). Community studies on adolescent substance use, abuse, or dependence and psychiatric comorbidity. J. Consult. Clin. Psychol. 70, 1224-1239. doi: 10.1037/0022-006X.70.6.1224

Arnett, J. J. (2002). Readings on Adolescence and Emerging Adulthood. Upper Saddle River, NJ: Prentice Hall.

Arseneault, L., Cannon, M., Poulton, R., Murray, R., Caspi, A., and Moffitt, T. E. (2002). Cannabis use in adolescence and risk for adult psychosis: longitudinal prospective study. Br. Med. J. 325, 1212-1213. doi: 10.1136/bmj.325.7374.1212

Aseltine, R. H., and Gore, S. (1998). The co-occurrence of depression and substance abuse in late adolescence. Dev. Psychopathol. 10, 549-570. doi: 10. 1017/S0954579498001746

Assari, S. (2018). Perceived discrimination and binge eating disorder; gender difference in African Americans. J. Clin. Med. 7:E89. doi: 10.3390/jcm70 50089

Assari, S., Caldwell, C. H., and Zimmerman, M. A. (2014). Sex differences in the association between testosterone and violent behaviors. Trauma Mon. 19:e18040. doi: 10.5812/traumamon. 18040

Assari, S., Mistry, R., and Caldwell, C. H. (in press). Perceived discrimination and substance use among caribbean black youth; gender differences. Brain Sci. 8:E131. doi: 10.3390/brainsci8070131

Assari, S., Moazen-Zadeh, E., Caldwell, C. H., and Zimmerman, M. A. (2017). Racial discrimination during adolescence predicts mental health deterioration in adulthood: gender differences among blacks. Front. Public Health 5:104. doi: 10.3389/fpubh.2017.00104

Assari, S., Smith, J. R., Caldwell, C. H., and Zimmerman, M. A. (2015). Gender differences in longitudinal links between neighborhood fear, parental support, and depression among African American emerging adults. Societies 5, 151-170. doi: $10.3390 / \operatorname{soc} 5010151$

Assari, S., Thomas, A., Caldwell, C. H., and Mincy, R. B. (2018). Blacks' diminished health return of family structure and socioeconomic status; 15 years of followup of a national Urban sample of youth. J. Urban Health 95, 21-35. doi: 10.1007/ s11524-017-0217-3

\section{FUNDING}

SA was supported by the Heinz C. Prechter Bipolar Research Fund and the Richard Tam Foundation at the University of Michigan Depression Center. This study was funded by the National Institute on Drug Abuse (NIDA) (Grant No. DA07484) to $\mathrm{MZ}$. The content of this article does not necessarily reflect the views or policies of the National Institute on Drug Abuse.

\section{SUPPLEMENTARY MATERIAL}

The Supplementary Material for this article can be found online at: https://www.frontiersin.org/articles/10.3389/fpsyg. 2018.02135/full\#supplementary-material

Bachman, J. G., Wadsworth, K. N., O’Malley, P. M., Johnston, L. D., and Schulenberg, J. (1997). Smoking, Drinking, and Drug Use in Young Adulthood: The Impacts of New Freedoms and New Responsibilities. Hillsdale, NJ: Lawrence Erlbaum Associates Inc.

Bahr, S. J., Maughan, S. L., Marcos, A. C., and Li, B. (1995). Family, educational and peer influences on the alcohol use of female and male adolescents. J. Stud. Alcohol 56, 457-469. doi: 10.15288/jsa.1995.56.457

Barber, B. K. (1992). Family, personality, and adolescent problem behaviors. J. Marriage Fam. 54, 66-79. doi: 10.2307/353276

Blazer, D. G., Kessler, R. C., McGonagle, K. A., and Swartz, M. S. (1994). The prevalence and distribution of major depression in a national community sample: the national comorbidity survey. Am. J. Psychiatry 151, 979-986. doi: 10.1176/ajp.151.7.979

Blazer, D. G., Landerman, L. R., Hays, J. C., Simonsick, E. M., and Saunders, W. B. (1998). Symptoms of depression among community-dwelling elderly africanamerican and white older adults. Psychol. Med. 28, 1311-1320. doi: 10.1017/ S0033291798007648

Block, R. I., O’Leary, D. S., Ehrhardt, J. C., Augustinack, J. C., Ghoneim, M. M., Arndt, S., et al. (2000). Effects of frequent marijuana use on brain tissue volume and composition. Neuroreport 11, 491-496. doi: 10.1097/00001756-20000228000013

Boden, J. M., Fergusson, D. M., and Horwood, L. J. (2010). Cigarette smoking and depression: tests of causal linkages using a longitudinal birth cohort. Br. J. Psychiatry 196, 440-446. doi: 10.1192/bjp.bp.109. 065912

Bovasso, G. (2001). Cannabis abuse as risk factor for depressive symptoms. Am. J. Psychiatry 158, 2033-2037. doi: 10.1176/appi.ajp.158.12.2033

Branstetter, S. A., Low, S., and Furman, W. (2011). The influence of parents and friends on adolescent substance use: a multidimensional approach. J. Subst. Use 16, 150-160. doi: 10.3109/14659891.2010.519421

Brenner, A. B., Bauermeister, J. A., and Zimmerman, M. A. (2011). Neighborhood variation in adolescent alcohol use: examination of socioecological and social disorganization theories. J. Stud. Alcohol Drugs 72, 651-659. doi: 10.15288/jsad. 2011.72.651

Brook, D. W., Brook, J. S., Zhang, C., Cohen, P., and Whiteman, M. (2002). Drug use and the risk of major depressive disorder, alcohol dependence, and substance use disorders. Arch. Gen. Psychiatry 59, 1039-1044. doi: 10.1001/ archpsyc.59.11.1039

Brook, J. S., Lee, J. Y., Brown, E. N., and Finch, S. J. (2012). Comorbid trajectories of tobacco and marijuana use as related to psychological outcomes. Subst. Abuse 33, 156-167. doi: 10.1080/08897077.2011.640202

Brown, R. A., Lewinsohn, P. M., Seeley, J. R., and Wagner, E. F. (1996). Cigarette smoking, major depression, and other psychiatric disorders among adolescents. J. Am. Acad. Child Adolesc. Psychiatry 35, 1602-1610. doi: 10.1097/00004583199612000-00011

Bukstein, O. G., Brent, D. A., Perper, J. A., Moritz, G., Baugher, M., Schweers, J., et al. (1993). Risk factors for completed suicide among adolescents with a lifetime history of substance abuse: a case-control study. Acta Psychiatr. Scand. 88, 403-408. doi: 10.1111/j.1600-0447.1993.tb03481.x 
Caggiula, A. R., Donny, E. C., Chaudhri, N., Perkins, K. A., Evans-Martin, F. F., and Sved, A. F. (2002). Importance of nonpharmacological factors in nicotine self-administration. Physiol. Behav. 77, 683-687. doi: 10.1016/S0031-9384(02) 00918-6

Caldwell, C., Assari, S., and Breland-Noble, A. M. (2016). "The epidemiology of mental disorders in African American children and adolescents," in Handbook of Mental Health in African American Youth, eds M. Breland-Noble, C. AlMateen, and N. Singh (Zurich: Springer International Publishing), 3-20.

Caldwell, C. H., Antonakos, C. L., Assari, S., Kruger, D., Loney, E. H., and Njai, R. (2014). Pathways to prevention: improving nonresident African American fathers' parenting skills and behaviors to reduce sons' aggression. Child Dev. 85, 308-325. doi: 10.1111/cdev.12127

Caldwell, C. H., Wright, J. C., Zimmerman, M. A., Walsemann, K. M., Williams, D., and Isichei, P. A. (2004). Enhancing adolescent health behaviors through strengthening non-resident father-son relationships: a model for intervention with African-American families. Health Educ. Res. 19, 644-656. doi: 10.1093/ her/cyg078

CDC. (1998). Youth risk behavior surveillance-United States, 1997. Morb. Mortal. Wkly. Rep. 47, 1-89.

CDC. (2000). Tobacco use among middle and high school students-United States, 1999. Morb. Mortal. Wkly. Rep. 49, 49-53.

CDC (2012). Fact Sheets: Alcohol use and Health. Available at: http://www.cdc.gov/ alcohol/fact-sheets/alcohol-use.htm

CDC (2013). Fact Sheet: Health Effects of Cigarette Smoking. Available at: http://www.cdc.gov/tobacco/data_statistics/fact_sheets/health_effects/effects_ cig_smoking/

Chabrol, H., Mabila, J. D., Chauchard, E., Mantoulan, R., and Rousseau, A. (2008). Contributions of parental and social influences to cannabis use in a non-clinical sample of adolescents. Encephale 34, 8-16. doi: 10.1016/j.encep.2007.01.002

Chen, K., and Kandel, D. B. (1998). Predictors of cessation of marijuana use: an event history analysis. Drug Alcohol Depend. 50, 109-121. doi: 10.1016/S03768716(98)00021-0

Childers, S. R., and Breivogel, C. S. (1998). Cannabis and endogenous cannabinoid systems. Drug Alcohol Depend. 51, 173-187. doi: 10.1016/S0376-8716(98) 00075- 1

Conrin, S. D., Zhan, L., Morrissey, Z. D., Xing, M., Forbes, A., Maki, P., et al. (2018). From default mode network to the basal configuration: sex differences in the resting-state brain connectivity as a function of age and their clinical correlates. Front. Psychiatry:9:365. doi: 10.3389/fpsyt.2018.00365

Cook, B. L., and Alegría, M. (2011). Racial-ethnic disparities in substance abuse treatment: the role of criminal history and socioeconomic status. Psychiatr. Serv. 62, 1273-1281. doi: 10.1176/ps.62.11.pss6211_1273

Copeland, E. P., and Hess, R. S. (1995). Differences in young adolescents' coping strategies based on gender and ethnicity. J. Early Adolesc. 15, 203-219. doi: 10.1177/0272431695015002002

Costello, E. J., Erkanli, A., Federman, E., and Angold, A. (1999). Development of psychiatric comorbidity with substance abuse in adolescents: effects of timing and sex. J. Clin. Child Psychol. 28, 298-311. doi: 10.1207/S15374424jccp280302

Crane, N. A., Langenecker, S. A., and Mermelstein, R. J. (2015). Gender differences in the associations among marijuana use, cigarette use, and symptoms of depression during adolescence and young adulthood. Addict. Behav. 24, 33-39. doi: 10.1016/j.addbeh.2015.05.014

Crane, N. A., Schuster, R. M., Fusar-Poli, P., and Gonzalez, R. (2013). Effects of cannabis on neurocognitive functioning: recent advances, neurodevelopmental influences, and sex differences. Neuropsychol. Rev. 23, 117-137. doi: 10.1007/s11065-012-9222-1

Cuijpers, P., Smit Ften Have, M., and de Graaf, R. (2007). Smoking is associated with first-ever incidence of mental disorders: a prospective population-based study. Addiction 102, 1303-1309. doi: 10.1111/j.1360-0443.2007.01885.x

Degenhardt, L., Hall, W., and Lynskey, M. (2003). Exploring the association between cannabis use and depression. Addiction 98, 1493-1504. doi: 10.1046/ j.1360-0443.2003.00437.x

Derogatis, L. R. (1977a). Scoring, and Procedures Manual for the (R)evised Version and other Instruments of the Psychopathology Rating Scale Series. Baltimore, MD: Johns Hopkins University Hospital.

Derogatis, L. R. (1977b). The SCL-90: Administration, Scoring, and Procedures Manual-I for Revised Version. Baltimore, MD: The Johns Hopkins University Hospital.
Derogatis, L. R., and Spencer, P. M. (1982). The Brief Symptom Inventory (BSI): Administration, Scoring and Procedures Manual-I. Baltimore, MD: Johns Hopkins University School of Medicine.

Derogatis, L. R., and Spencer, P. M. (1993). Brief Symptom Inventory: BSI. Upper Saddle River, NJ: Pearson.

Dishion, T. J., and Loeber, R. (1985). Adolescent marijuana and alcohol use: the role of parents and peers revisited. Am. J. Drug Alcohol Abuse 11, 11-25. doi: 10.3109/00952998509016846

Elkington, K. S., Bauermeister, J. A., and Zimmerman, M. A. (2011). Do parents and peers matter? A prospective socio-ecological examination of substance use and sexual risk among African American youth. J. Adolesc. 34, 1035-1047. doi: 10.1016/j.adolescence.2010.11.004

Farrell, A. D., and White, K. S. (1998). Peer influences and drug use among urban adolescents: family structure and parent-adolescent relationship as protective factors. J. Consult. Clin. Psychol. 66, 248-258. doi: 10.1037/0022-006X. 66.2.248

Fergusson, D. M., and Horwood, L. J. (1997). Early onset cannabis use and psychosocial adjustment in young adulthood. Addiction 92, 279-296. doi: 10. 1111/j.1360-0443.1997.tb03198.x

Fergusson, D. M., Horwood, L. J., and Swain-Campbell, M. (2002). Cannabis use and psychosocial adjustment in adolescence and young adulthood. Addiction 97, 1123-1135. doi: 10.1046/j.1360-0443.2002.00103.x

Gerrard, M., Stock, M. L., Roberts, M. E., Gibbons, F. X., O’Hara, R. E., Weng, C. Y., et al. (2012). Coping with racial discrimination: the role of substance use. Psychol. Addict. Behav. 26, 550-560. doi: 10.1037/a0027711

Gore, S., and Aseltine, R. H. Jr. (2003). Race and ethnic differences in depressed mood following the transition from high school. J. Health Soc. Behav. 44, 370-389. doi: 10.2307/1519785

Green, B. E., and Ritter, C. (2000). Marijuana use and depression. J. Health Soc. Behav. 41, 40-49. doi: 10.2307/2676359

Griffin, K. W., and Botvin, G. J. (2010). Evidence-based interventions for preventing substance use disorders in adolescents. Child Adolesc. Psychiatr. Clin. North Am. 19, 505-526. doi: 10.1016/j.chc.2010.03.005

Griffin, K. W., Botvin, G. J., Scheier, L. M., Diaz, T., and Miller, N. L. (2000). Parenting practices as predictors of substance use, delinquency, and aggression among urban minority youth: moderating effects of family structure and gender. Psychol. Addict. Behav. 14, 174-184. doi: 10.1037/0893-164X.14. 2.174

Hamilton, J. E., Heads, A. M., Cho, R. Y., Lane, S. D., and Soares, J. C. (2015). Racial disparities during admission to an academic psychiatric hospital in a large urban area. Compr. Psychiatry 63, 113-122. doi: 10.1016/j.comppsych.2015. 08.010

Hankin, B. L., and Abramson, L. Y. (1999). Development of gender differences in depression: description and possible explanations. Ann. Med. 31, 372-379. doi: 10.3109/07853899908998794

Hankin, B. L., Mermelstein, R., and Roesch, L. (2007). Sex differences in adolescent depression: Stress exposure and reactivity models. Child Dev. 78, 279-295. doi: 10.1111/j.1467-8624.2007.00997.x

Hawkins, J. D., Catalano, R. F., and Arthur, M. W. (2002). Promoting science-based prevention in communities. Addict. Behav. 27, 951-976. doi: 10.1016/S03064603(02)00298-8

Hayatbakhsh, M. R., Najman, J. M., Jamrozik, K., Mamun, A., AAlati, R., and Bor, W. (2007). Cannabis and anxiety and depression in young adults: a large prospective study. J. Am. Acad. Child Adolesc. Psychiatry 46, 408-417. doi: $10.1097 /$ chi.0b013e31802dc54d

Hu, L., and Bentler, P. M. (1999). Cutoff criteria for fit indexes in covariance structure analysis: conventional criteria versus new alternatives. Struct. Equat. Model. 6, 1-55. doi: 10.1080/10705519909540118

Iversen, L. (2003). Cannabis and the brain. Brain 126, 1252-1270. doi: 10.1093/ brain/awg143

Jackson, J. S., Knight, K. M., and Rafferty, J. A. (2010). Race and unhealthy behaviors: chronic stress, the HPA axis, and physical and mental health disparities over the life course. Am. J. Public Health 100, 933-939. doi: 10.2105/ AJPH.2008.143446

Johnston, L. D., O’Malley, P. M., Miech, R. A., Bachman, J. G., and Schulenberg, J. E. (2014). Monitoring the Future National Results on Adolescent Drug Use: Overview of Key Findings, 2013. Ann Arbor, MI: The University of Michigan, 90 
Jones-Webb, R. J., and Snowden, L. R. (1993). Symptoms of depression among blacks and whites. Am. J. Public Health 83, 240-244. doi: 10.2105/AJPH.83. 2.240

Kandel, D. B. (1984). Marijuana users in young adulthood. Arch. Gen. Psychiatry 41, 200-209. doi: 10.1001/archpsyc.1984.01790130096013

Kandel, D. B., Johnson, J., Bird, H., Canino, G., Goodman, S., Regier, D. A., et al. (1997). Psychiatric disorders associated with substance use among children and adolescents: findings from the methods for the Epidemiology of child and adolescent mental disorders (MECA study). J. Abnorm. Child Psychol. 25, 121-132. doi: 10.1023/A:1025779412167

Kessler, R. C., McGonagle, K. A., Zhao, S., Nelson, C. B., Hughes, M., Eshleman, S., et al. (1994). Lifetime and 12-month prevalence of dsm-iii-r psychiatric disorders in the united states. Results from the national comorbidity survey. Arch. Gen. Psychiatry 51, 8-19. doi: 10.1001/archpsyc.1994.03950010008002

King, C. A., Ghaziuddin, N., McGovern, L., Brand, E., Hill, E., and Naylor, M. (1996). Predictors of comorbid alcohol and substance abuse in depressed adolescents. J. Am. Acad. Child Adolesc. Psychiatry 35, 743-751. doi: 10.1097/ 00004583-199606000-00014

Kline, R. B. (2011). Principles and Practice of Structural Equation Modeling. New York, NY: Guilford press.

Klungsoyr, O., Nygard, J. F., Sorensen, T., and Sandanger, I. (2006). Cigarette smoking and incidence of first depressive episode: an 11-year, population-based follow-up study. Am. J. Epidemiol. 163, 421-432. doi: 10.1093/ajek/wj058

Knight, D. K., Broome, K. M., Cross, D. R., and Simpson, D. D. (1998). Antisocial tendency among drug-addicted adults: potential long-term effects of parental absence, support, and conflict during childhood. Am. J. Drug Alcohol Abuse 24, 361-375. doi: 10.3109/00952999809016903

Kock, N. (2014). Advanced mediating effects tests, multi-group analyses, and measurement model assessments in PLS-based SEM. Int. J. e Collab. 10, 1-13. doi: 10.4018/ijec.2014010101

Kuehner, C. (2003). Gender differences in unipolar depression: an update of epidemiological findings and possible explanations. Acta Psychiatr. Scand. 108, 163-174. doi: 10.1034/j.1600-0447.2003.00204.x

Lei, M., and Lomax, R. G. (2005). The effect of varying degrees of nonnormality in structural equation modeling. Struct. Equat. Model. 12, 1-27. doi: 10.1207/ s15328007sem1201_1

Lei, X., Han, Z., Chen, C., Bai, L., Xue, G., and Dong, Q. (2016). Sex differences in fiber connection between the striatum and subcortical and cortical regions. Front. Comput. Neurosci. 10:100. doi: 10.3389/fncom.2016. 00100

Libby, A. M., Orton, H. D., Stover, S. K., and Riggs, P. D. (2005). What came first, major depression or substance use disorder? Clinical characteristics and substance use comparing teens in a treatment cohort. Addict. Behav. 30, 1649-1662. doi: 10.1016/j.addbeh.2005.07.012

Mallin, R., Slott, K., Tumblin, M., and Hunter, M. (2002). Detection of substance use disorders in patients presenting with depression. Subst. Abuse 23, 115-120. doi: 10.1080/08897070209511481

Matochik, J. A., Eldreth, D. A., Cadet, J. L., Bolla, K. I. (2005). Altered brain tissue composition in heavy marijuana users. Drug Alcohol Depend. 77, 23-30. doi: 10.1016/j.drugalcdep.2004.06.011

Martin, C. S., Kaczynski, N. A., Maisto, S. A., and Tarter, R. E. (1996). Polydrug use in adolescent drinkers with and without DSM-IV alcohol abuse and dependence. Alcohol. Clin. Exp. Res. 20, 1099-1108. doi: 10.1111/j.1530-0277. 1996.tb01953.x

Mathers, M., Toumbourou, J. W., Catalano, R. F., Williams, J., and Patton, G. C. (2006). Consequences of youth tobacco use: a review of prospective behavioural studies. Addiction 101, 948-958. doi: 10.1111/j.1360-0443.2006. 01438.x

McKenna, G. J. (2014). The current status of medical marijuana in the United States. Hawaii J. Med. Public Health 73, 105-108.

Medina, K. L., McQueeny, T., Nagel, B. J., Hanson, K. L., Yang, T. T., and Tapert, S. F. (2009). Prefrontal cortex morphometry in abstinent adolescent marijuana users: subtle gender effects. Addict. Biol. 14, 457-468. doi: 10.1111/j.1369-1600. 2009.00166.x

Medina, K. L., Nagel, B. J., Park, A., McQueeny, T., and Tapert, S. F. (2007). Depressive symptoms in adolescents: associations with white matter volume and marijuana use. J. Child Psychol. Psychiatry 48, 592-600. doi: 10.1111/j.14697610.2007.01728.x
Menke, R., and Flynn, H. (2009). Relationships between stigma, depression, and treatment in white and African American primary care patients. J. Nerv. Ment. Dis. 197, 407-411. doi: 10.1097/NMD.0b013e3181a6162e

Mennis, J., and Stahler, G. J. (2016). Racial and ethnic disparities in outpatient substance use disorder treatment episode completion for different substances. J. Subst. Abuse Treat. 63, 25-33. doi: 10.1016/j.jsat.2015.12.007

Mericle, A. A., Park, V. M. T., Holck, P., and Arria, A. M. (2012). Prevalence, patterns, and correlates of co-occurring substance use and mental disorders in the United States: variations by race/ethnicity. Compr. Psychiatry 53, 57-65. doi: 10.1016/j.comppsych.2011.10.002

Miech, R. A., Johnston, L. D., O’Malley, P. M., Bachman, J. G., et al. (2017). Monitoring the Future National Survey Results on Drug Use, 1975-2016: Volume I, Secondary School Students. Ann Arbor, MI: The University of Michigan, 683.

Miller, B., and Taylor, J. (2012). Racial and socioeconomic status differences in depressive symptoms among black and white youth: an examination of the mediating effects of family structure, stress and support. J. Youth Adolesc. 41, 426-437. doi: 10.1007/s10964-011-9672-4

Onders, B., Casavant, M. J., Spiller, H. A., Chounthirath, T., and Smith, G. A. (2015). Marijuana exposure among children younger than six years in the United States. Clin. Pediatr. 55, 428-436. doi: 10.1177/0009922815589912

Ozer, E. J., Flores, E., Tschann, J. M., and Pasch, L. A. (2013). Parenting style, depressive symptoms, and substance use in mexican american adolescents. Youth Soc. 45, 365-388. doi: 10.1177/0044118X11418539

Pacek, L. R., Malcolm, R. J., and Martins, S. S. (2012). Race/ethnicity differences between alcohol, marijuana, and co-occurring alcohol and marijuana use disorders and their association with public health and social problems using a national sample. Am. J. Addict. 21, 435-444. doi: 10.1111/j.1521-0391.2012. 00249.x

Patton, G. C., Coffey, C., Carlin, J. B., Degenhardt, L., Lynskey, M., and Hall, W. (2002). Cannabis use and mental health in young people: cohort study. Br. Med. J. 325, 1195-1198. doi: 10.1136/bmj.325.7374.1195

Patton, G. C., Coffey, C., Carlin, J. B., Sawyer, S. M., and Lynskey, M. (2005). Reverse gateways? Frequent cannabis use as a predictor of tobacco initiation and nicotine dependence. Addiction 100, 1518-1525. doi: 10.1111/j.1360-0443. 2005.01220.x

Pedersen, W., and von Soest, T. (2009). Smoking, nicotine dependence and mental health among young adults: A 13-year population-based longitudinal study. Addiction 104, 129-137. doi: 10.1111/j.1360-0443.2008. 02395.x

Peters, E. N., Hendricks, P. S., Clark, C. B., Vocci, F. J., and Cropsey, K. L. (2014). Association of race and age with treatment attendance and completion among adult marijuana users in community-based substance abuse treatment. J. Addict. Med. 8, 143-149. doi: 10.1097/ADM.0000000000000030

Piccinelli, M., and Wilkinson, G. (2000). Gender differences in depression. Critical review. Br. J. Psychiatry 177, 486-492. doi: 10.1192/bjp.177.6.486

Pistis, M., Perra, S., Pillolla, G., Melis, M., Muntoni, A. L., and Gessa, G. L. (2004). Adolescent exposure to cannabinoids induces long-lasting changes in the response to drugs of abuse of rat midbrain dopamine neurons. Biol. Psychiatry 56, 86-94. doi: 10.1016/j.biopsych.2004.05.006

Procidano, M. E., and Heller, K. (1983). Measures of perceived social support from friends and from family: three validation studies. Am. J. Community Psychol. 11, 1-24. doi: $10.1007 / B F 00898416$

Ralston, E. S., Trudeau, L. S., and Spoth, R. (2012). Effects of parent-child affective quality during high school years on subsequent substance use. Int. J. Emot. Educ. $4,25-42$.

Rao, U., Daley, S. E., and Hammen, C. (2000). Relationship between depression and substance use disorders in adolescent women during the transition to adulthood. J. Am. Acad. Child Adolesc. Psychiatry 39, 215-222. doi: 10.1097/ 00004583-200002000-00022

Rao, U., Ryan, N. D., Dahl, R. E., Birmaher, B., Rao, R., Williamson, D. E., et al. (1999). Factors associated with the development of substance use disorder in depressed adolescents. J. Am. Acad. Child Adolesc. Psychiatry 38, 1109-1117. doi: 10.1097/00004583-199909000-00014

Repetto, P. B., Zimmerman, M. A., and Caldwell, C. H. (2008). A longitudinal study of depressive symptoms and marijuana use in a sample of inner-city African Americans. J. Res. Adolesc. 18, 421-447. doi: 10.1111/j.1532-7795.2008.00566.x

Riggs, P. D., Baker, S., Mikulich, S. K., Young, S. E., and Crowley, T. J. (1995). Depression in substance-dependent delinquents. J. Am. Acad. 
Child Adolesc. Psychiatry 34, 764-771. doi: 10.1097/00004583-19950600000017

Rohde, P., Lewinsohn, P. M., and Seeley, J. R. (1991). Comorbidity of unipolar depression: II. Comorbidity with other mental disorders in adolescents and adults. J. Abnorm. Psychol. 100, 214-222. doi: 10.1037/0021-843X.100.2.214

Rohde, P., Lewinsohn, P. M., and Seeley, J. R. (1996). Psychiatric comorbidity with problematic alcohol use in high school students. J. Am. Acad. Child Adolesc. Psychiatry 35, 101-109. doi: 10.1097/00004583-199601000-00018

Romero, J., Garcia-Palomero, E., Berrendero, F., Garcia-Gil, L., Hernandez, M. L., Ramos, J. A., et al. (1997). Atypical location of cannabinoid receptors in white matter areas during rat brain development. Synapse 27, 317-323. doi: 10.1002/ (SICI) 1098-2396(199707)26:3<317::AID-SYN12>3.0.CO;2-S

Romero, J., Hillard, C. J., Calero, M., and Rabano, A. (2002). Fatty acid amide hydrolase localization in the human central nervous system: an immunohistochemical study. Mol. Brain Res. 100, 85-93. doi: 10.1016/S0169328X(02)00167-5

Salem, D. A., Zimmerman, M. A., and Notaro, P. C. (1998). Effects of family structure, family process, and father involvement on psychosocial outcomes among african american adolescents. Fam. Relat. 47, 331-341. doi: 10.2307/ 585264

SAMSHA (2013). Results from the 2012 National Survey on Drug Use and Health: Summary of National Findings. Available at: http://www.samhsa.gov/ data/NSDUH/2012SummNatFindDetTables/index.aspx

Scaramella, L. V., Conger, R. D., and Simons, R. L. (1999). Parental protective influences and gender-specific increases in adolescent internalizing and externalizing problems. J. Res. Adolesc. 9, 111-141. doi: 10.1207/ s15327795jra0902_1

Schildhaus, S., and Dugoni, B. (2012). Premature death as the ultimate failure: predictors of death in the US drug user treatment population. Subst. Use Misuse 47, 1666-1669. doi: 10.3109/10826084.2012.706165

Schulenberg, J. E., Johnston, L. D., O’Malley, P. M., Bachman, J. G., Miech, R. A., and Patrick, M. E. (2017). Monitoring the Future National Survey Results on Drug use, 1975-2016: Volume II, College Students and Adults Ages 19-55. Ann Arbor, MI: The University of Michigan, 445.

Schulte, M. T., Ramo, D., and Brown, S. A. (2009). Gender differences in factors influencing alcohol use and drinking progression among adolescents. Clin. Psychol. Rev. 29, 535-547. doi: 10.1016/j.cpr.2009.06.003

Schuster, R. M., Mermelstein, R., and Wakschlag, L. (2013). Gender-specific relationships between depressive symptoms, marijuana use, parental communication and risky sexual behavior in adolescence. J. Youth Adolesc. 42, 1194-1209. doi: 10.1007/s10964-012-9809-0

Settersten, R. A., and Ray, B. (2010). What's going on with young people today? The long and twisting path to adulthood. Fut. Child 20, 20-41.

Shrier, L. A., Walls, C. E., Kendall, A. D., and Blood, E. A. (2012). The context of desire to use marijuana: momentary assessment of young people who frequently use marijuana. Psychol. Addict. Behav. 26, 821-829. doi: 10.1037/a0029197

Silins, E., Horwood, J. L., Patton, G. C., Fergusson, D. M., Olsson, C. A., Hutchinson, D. M., et al. (2014). Young adult sequelae of adolescent cannabis use: an integrative analysis. Lancet Psychiatry 1, 286-293. doi: 10.1016/S22150366(14)70307-4

Simoni, J. M., Huh, D., Wilson, I. B., Shen, J., Goggin, K., Reynolds, N. R., et al. (2012). Racial/Ethnic disparities in ART adherence in the United States: findings from the MACH14 study. J. Acquir. Immune Defic. Syndr. 60, 466-472. doi: 10.1097/QAI.0b013e31825db0bd

Stiglick, A., and Kalant, H. (1985). Behavioral effects of prolonged administration of delta 9- Tetrahydro-cannabinol in the rat. Psychopharmacology 80, 325-330. doi: 10.1007/BF00432114

Swendsen, J., and Merinkangas, K. (2000). The comorbidity of depression and substance use disorders. Clin. Psychol. Rev. 20, 207-234. doi: 10.1016/S02727358(99)00026-4

Tabachnick, B. G., and Fidell, L. S. (1996). Using Multivariate Statistics, 3rd Edn. New York, NY: HarperCollins.

Tucker, J. A., Cheong, J., Chandler, S. D., Crawford, S. M., and Simpson, C. A. (2015). Social networks and substance use among at-risk emerging adults living in disadvantaged urban areas in the southern United States: a cross-sectional naturalistic study. Addiction 110, 1524-1532. doi: 10.1111/add.13010
Valiente, C., Romero, N., Hervas, G., and Espinosa, R. (2014). Evaluative beliefs as mediators of the relationship between parental bonding and symptoms of paranoia and depression. Psychiatry Res. 30, 75-81. doi: 10.1016/j.psychres. 2013.10.014

van Laar, M., van Dorsselaer, S., Monshouwer, K., and de Graaf, R. (2007). Does cannabis use predict the first incidence of mood and anxiety disorders in the adult population? Addiction 102, 1251-1260.

Verdejo-García, A., López-Torrecillas, F., Giménez, C. O., and Pérrez-García, M. (2004). Clinical implications and methodological challenges in the study of the neuropsychological correlates of cannabis, stimulant, and opioid abuse. Neuropsychol. Rev. 14, 1-41. doi: 10.1023/B:NERV.0000026647.71528.83

Volkow, N. D. (2004). The reality of comorbidity: depression and drug abuse. Biol. Psychiatry 56, 714-717. doi: 10.1016/j.biopsych.2004.07.007

Wallace, J. M. Jr., and Bachman, J. G. (1993). "Validity of self-reports in student based studies on minority populations: issues and concerns," in Drug Abuse Among Minority Youth: Methodological Issues and Recent Research Advances, eds M. DeLaRosa and J. L. Adrados (Washington, DC: Department of Health and Human Services), 167-200.

Wallace, JM Jr, Forman, T. A., Guthrie, B. J., Bachman, J. G., O’Malley, P. M., and Johnston, L. D. (1999). The epidemiology of alcohol, tobacco and other drug use among Black youth. J. Stud. Alcohol 60, 800-809. doi: 10.15288/jsa.1999. 60.800

Watts, W. D., and Wright, L. S. (1990). The relationship of alcohol, tobacco, marijuana, and other illegal drug use to delinquency among MexicanAmerican, black, and with adolescent males. Adolescence 25, 171-181.

Weinstein, S. M., and Mermelstein, R. J. (2013). Influences of mood variability, negative moods, and depression on adolescent cigarette smoking. Psychol. Addict. Behav. 27, 1068-1078. doi: 10.1037/a0031488

Whitmore, E. A., Mikulich, S. K., Thompson, L. L., Riggs, P. D., Aarons, G. A., and Crowley, T. J. (1997). Influences on adolescent substance dependence: conduct disorder, depression, attention deficit hyperactivity disorder, and gender. Drug Alcohol Depend. 47, 87-97. doi: 10.1016/S0376-8716(97)00074-4

Williams, D. R., Gonzalez, H. M., Neighbors, H., Nesse, R., Abelson, J. M., Sweetman, J., et al. (2007). Prevalence and distribution of major depressive disorder in african americans, caribbean blacks, and non-hispanic whites: results from the National Survey of American Life. Arch. Gen. Psychiatry 64, 305-315. doi: 10.1001/archpsyc.64.3.305

Wills, T. A., Gibbons, F. X., Gerrard, M., and Brody, G. (2000). Protection and vulnerability processes for early onset of substance use: a test among African American children. Health Psychol. 19, 253-263. doi: 10.1037/02786133.19 .3 .253

Wills, T. A., Mariani, J., and Filer, M. (1996). "The role of family and peer relationships in adolescent substance use," in Handbook of Social Support and the Family, eds G. R. Pierce, B. R. Sarason, and I. G. Sarason (New York, NY: Plenum), 521-549.

Wills, T. A., Resko, J. A., Ainette, M. G., and Mendoza, D. (2004). Role of parent support and peer support in adolescent substance use: a test of mediated effects. Psychol. Addict. Behav. 18, 122-134. doi: 10.1037/0893-164X.18.2.122

Wills, T. A., and Vaughan, R. (1989). Social support and substance use in early adolescence. J. Behav. Med. 12, 321-339. doi: 10.1007/BF00844927

Wilson, W., Mathew, R., Turkington, T., Hawk, T., Coleman, R. E., and Provenzale, J. (2000). Brain morphological changes and early marijuana use: a magnetic resonance and positron emission tomography study. J. Addict. Dis. 19, 1-22. doi: 10.1300/J069v19n01_01

Conflict of Interest Statement: The authors declare that the research was conducted in the absence of any commercial or financial relationships that could be construed as a potential conflict of interest.

Copyright ( 2018 Assari, Mistry, Caldwell and Zimmerman. This is an open-access article distributed under the terms of the Creative Commons Attribution License (CC BY). The use, distribution or reproduction in other forums is permitted, provided the original author(s) and the copyright owner(s) are credited and that the original publication in this journal is cited, in accordance with accepted academic practice. No use, distribution or reproduction is permitted which does not comply with these terms. 